\title{
Édipo, tirania e verdade ${ }^{1}$
}

Oedipus, tyranny and truth

\author{
Alberto Pucheu \\ UFRJ, CNPq, FAPERJ
}

\section{Resumo}

Em Édipo Rei, há uma cena que já foi dita ser a cesura, o antirrítimo no ritmo, o incalculável no cálculo: a do tirano com Tirésias. Como o vidente é dito ser aquele em quem "[...] só/ se infunde o Desocultamento: Alétheia", leio tal cena como uma cena de alétheia, como uma cena em que alétheia se encena. Certamente, é uma cena análoga ao que é contado da relação de Édipo com a Esfinge, em que esta resguarda o enigmático, enquanto aquele acredita na decifração do enigmático. Se Édipo é, como diz, o investigador de todos os discursos, como ele se porta em relação a isso que, na linguagem, enquanto alétheia, é o que mais importa? Do mesmo modo, como Tirésias se porta? Como a linguagem porta alétheia que nela aporta? Enquanto, em sua posição frente à verdade, Édipo assume uma posição de tirania, em Tirésias, alétheia e aporia se sobrepõem, fazendo-nos pensar, se ainda nos for preciso usar o nome, em uma "verdade" aporética como a que poeticamente nos cabe. Assim, haveria um duplo paradigma na respectiva tragédia quanto ao modo de pensar a verdade: um a ser evitado, o de Édipo; outro, a ser seguido, o de Tirésias.

Palavras-chaves: Édipo; tirania; verdade; Tirésias; aporia

\begin{abstract}
In Oedipus the King, there is a scene that has already been said to be the caesura, the antirhythmic in the rhythm, the incalculable in the calculation: that of the tyrant with Tiresias. As the seer is said to be the one in whom "[...] only/ the unveiling is infused: Aletheia", I read this scene as a scene from aletheia, as a scene in which aletheia is enacted. Certainly, it is a scene analogous to what is told of the relationship between Oedipus and the Sphinx, in which the Sphinx protects the enigmatic, while the other one believes in deciphering the enigmatic. If Oedipus is, as he says, the investigator of all speeches, how does he behave in relation to that which, in language, as aletheia, is what matters most? Likewise, how does Tiresias behave? While, in his position in front of the truth, Oedipus assumes a position of tyranny, in Tiresias, aletheia and aporia overlap, making us think, if we still need to use the name, in an aporetic "truth" like the one that poetically matters. Thus, there would be a double paradigm in the respective tragedy regarding the way of thinking the truth: one to be avoided, that of Oedipus; another one, to be followed, that of Tiresias.
\end{abstract}

Keywords: Oedipus; tyranny; truth; Tiresias; aporia

1 Este texto vem se acrescentar a dois outros que publiquei sobre a tragédia Édipo Rei, complementando-os: Giorgio Agamben: poesia, filosofia, crítica. Rio de Janeiro: Azougue Editorial, 2010. Capítulo 4 (sem título); e, "Édipo Rei: aporia, enigma, paradigma". IN: Que porra é essa - poesia? Rio de Janeiro: Azougue Editorial, 2018. p. 271-278. Ambos podem ser encontrados no meu site: http://www.albertopucheu.com.br/livros.html. 
Em Édipo Rei, há uma cena que, indo contra as expectativas do herói, traz surpresa a ele, a outras personagens, ao coro e aos espectadores, mostrando, na peripécia, na reversibilidade do esperado, a complexidade do mito, o paradoxo que se encontra em jogo na tragédia. $\mathrm{O}$ que serviria - sendo mesmo necessário - para a salvação da cidade e, atrelado a ela, para o reconhecimento dos melhores atos daquele que até então era considerado o de maior excelência, o primeiro, o salvador, o mais sábio e o mais poderoso, acaba, a contrapelo, fazendo recair o efeito contrário sobre o herói. Defendido na denegação do que se lhe apresenta, Édipo, a princípio, não se reconhece no dito reversivo e adia o reconhecimento efetivo, tardando a saber quem de fato é o criminoso procurado que deve ser punido para livrar a cidade dos males, das dores e das mortes que a subjugam. Nessa cena, o passado e o futuro convergem na fratura do presente.

Por esse intervalo subversivo do que se passa entre duas personagens, por essa interrupção entre Édipo e Tirésias, por essa cisão de Édipo consigo mesmo, por esse rasgo entre o herói e os deuses, por essa fratura na continuidade da tragédia, por esse corte trágico, por essa ferida entre uma força privilegiadamente religiosa e outra predominantemente política cujas palavras, ainda que distintas, têm (pelo menos, a princípio, teriam) pesos afins, por entre uma demanda tirânica e uma resistência obrigada finalmente a ceder realizando a demanda de falar o que vê e que ninguém mais enxerga, se dá a torrente avassaladora da transformação que vem, a "cesura", como Hölderlin a denominou ${ }^{1}$, o incalculável no cálculo, o antirrítmico no ritmo, a mostragem encenada da compreensão trágica daquilo que habitualmente chamamos imprecisamente de verdade, e que os gregos chamaram de alétheia, desocultamento, desvelamento, aquilo que não pode, de modo algum, ser esquecido.

Convocado pelo coro e pelo tirano, esse que vem para a cena é chamado por aquele de "o divino profeta”, em quem "[...] só/ se infunde o Desocultamento: Alétbeia”. Mais do que todos os outros homens, Tirésias é quem traz, implantada nele, pela mântica, alétheia. A experiência de alétheia é o que Tirésias tem a oferecer a Édipo quando este o chama, ou melhor, quando este o obriga a, contrariado, vir à sua presença. O que, ignorado por ele mesmo, diz respeito à história de Édipo vem-lhe consecutivamente de fora. O saber da vida de Édipo lhe vem do exterior, do outro, das alteridades. A alétheia acerca de sua vida não lhe vem de si, mas de fora, dos outros, cujos discursos, a partir do necessário proferimento oracular, ele investiga sem saber que o constituem, sem saber que o oráculo fala, enigmaticamente, dele, Édipo, ou sem saber que, na fala do oráculo, é ele, Édipo, o calado, o silenciado, para que, na investigação de todas

1 HÖLDERLIN, Friedrich. Observações sobre Édipo, 2008, p. 69.

2 SÓFOCLES. Édipo Rei, 2007, p. 51. 
as indicações linguísticas, os outros possam então, ainda que contrariadamente, falar do que o constitui. Os outros que falam do que diz respeito a Édipo são: Tirésias, Creonte (para quem Édipo desliza a revelação de Tirésias), Jocasta (indiretamente, pelo que ela lhe conta, como do oráculo dito a Laio antes do nascimento de Édipo e de seu assassinato na tripla encruzilhada das estradas), o bêbado no palácio em Corinto, Apolo (diversas vezes, mas diretamente a Édipo quando ele foi consultar o oráculo), o mensageiro de Corinto (que vem avisar Édipo da morte de Políbio) e, finalmente, o servo pastor de Laio. São desses discursos de outros que Édipo diz ser o investigador, sendo ele, sobretudo, o investigado.

De modo muito especial, dentre todos esses discursos, há o de Tirésias, que, ao se equivaler à alétheia, mostra, igualmente, a dimensão poética da tragédia tão necessária à filosofia e à política, fazendo dessas uma extração singular da poesia. O fato de, em sua tradução, Trajano Vieira ter colocado sua versão para a respectiva palavra em maiúsculas e de tê-la redobrado, deixando-a tanto em português quanto em grego transliterado, mostra a importância decisiva de tal palavra, de tal experiência, para a cena. Na cena, que é precedida e seguida pelo coro que nela tem uma breve participação no intuito de, atravessando-a, dizer que o que importa não é a ira das duas personagens, mas, sim, solucionar o enigmático oráculo délfico, será repetido que o vidente é aquele em quem alétheia prevalece (îㅈvov), o que é forte em alétheia, aquele que lhe é equivalente, que corresponde a ela, tendo ele, fundido a ela, o valor de alétbeia. Tal cena pode ser lida como uma cena de alétheia, como uma cena em que alétheia se encena.

Nessa encenação de alétbeia, faz-se presente o protagonista, Édipo, o tirano, o rei, o melhor, o mais poderoso, o mais sábio, o salvador, o que por, supostamente, ter derrotado a Esfinge, acredita que tudo vê, que tudo sabe, que tudo pode ser dito, que tudo pode ser clarificado, que, lutando pela saúde da cidade no momento "sem fruto, sem o deus, sem vida, nada" ${ }^{3}$ e, então, pelo nome de Laio, acredita lutar igualmente pelo deus, pelas palavras de Apolo, pelo oráculo recém-proferido pelo deus. Em tal cena, também, o antagonista, Tirésias (ou de quem ele é sacerdote, Apolo), o vidente que, não à toa, é cego, que se confunde com alétheia e, confundindo-se com alétheia, confunde-se igualmente com Apolo. Entre o que tudo quer ver e o cego vidente, como fica alétheia? Certamente, é uma cena análoga ao que é contado da relação de Édipo com a Esfinge, em que esta resguarda o enigmático, enquanto aquele acredita na decifração do enigmático. Se Édipo é, como diz, o investigador de todos os discursos, de todos os ditos, de todas as hipóteses (v. 291), como ele se porta em relação a isso que, na linguagem, enquanto alétheia, é o que mais importa? Do mesmo modo, como Tirésias se porta? Como a linguagem porta alétheia que nela aporta?

3 Ibidem, v. 254, p. 49. 
Imediatamente antes, no diálogo com o coro, Édipo havia feito uma proclamação, proferido uma imprecação, dado uma ordem geral (seguida, depois, de outras, nuançadas) que causa temor em todos dadas as consequências que pode ter, a morte ou o exílio: "se alguém souber que mãos mataram Laio,/ filho de Lábdaco, a esse alguém ordeno/ que se apresente a mim e conte tudo". Logo depois, no verso 258, na mesma fala, ele diz "mister é esclarecer"; pouco adiante, ainda na conversa com o coro, no verso 282 , a mesma pretensão exclusivamente clarificadora: "Não omitas nada". Na sequência, já em diálogo com Tirésias, Édipo diz "não ocultes" (v. 310); diante do fato de Tirésias não querer falar, o tirano segue, com irritação extrema: "Será que entendo bem? Sabendo, calas?" (v. 330), "Seu miserável mor! Não falarás?" (v. 334). Um Édipo totalmente desnorteado dispara finalmente contra Tirésias: "Já nada fica implícito - motiva-me/ a fúria: arquitetaste o assassinato" (vs. 345-346). Em 358, ele insiste: "Fala! Assim eu me elucido". Em 361, com Trajano Vieira concordando com tudo isso que está se passando em grego, Édipo exige a Tirésias: "Aclara!".

Eis traços da tirania: retirando do outro suas possibilidades de decisão, suas potencialidades que lhe cabem, o tirano traz essa exigência e obrigação de que o outro conte tudo, de que o outro esclareça absolutamente tudo, de que o outro não omita nada, de que o outro não oculte nada, de que o outro não possa se calar, de que o outro tenha de aclarar tudo para que ele, Édipo, enfim, se elucide. Em total equívoco, em sua imaginação adulterada, em sua derrocada final e fatal como pretendente de alétheia, que, para Édipo, se caracteriza por variações de um "já nada fica implícito", já que, para ele, o que se esclarece ou se elucida ou se aclara ou se explicita completamente é o mais disparatado, o mais despropositado, o mais afastado de alétheia: o imaginário de que fora Tirésias quem havia matado ou mandado matar Laio. Se ler essa disparatada possibilidade interpretativa do que se passa é erro absurdo de Édipo, seu erro ainda maior, o que o afasta de alétheia, é acreditar que uma interpretação qualquer possa explicitar tudo, sem deixar nada implícito. Sabe-se que a tirania, ou o autoritarismo, não se vincula apenas à proibição da fala, mas, igualmente, à obrigação da fala, ao não poder não dizer - países que tiveram ou têm ditaduras e torturas conhecem bem isso.

Amplamente equivocada a respeito de alétheia, tal posição edipiana se agrava ainda mais se lembrarmos as primeiras palavras do tirano dirigidas a Tirésias quando da chegada deste. Édipo afirma: "Tirésias, pan-senhor telúrio-urânico/ do que se diz e cala no silêncio". Como exigir um total esclarecimento, um total aclaramento, uma explicitação total, como exigir nenhuma omissão nem nenhuma ocultação nem nada implícito no dizer, como exigir a

4 Ibidem, v. 224-226, p.48.

5 Ibidem, v.282., p.50.

6 Ibidem, v.300-301, p. 51. 
obrigatoriedade de falar tudo, como exigir isso, especialmente a esse que Édipo sabe ser pansenhor do dizer e do calar, pan-guia do dizer e do silêncio, como exigir isso desse que se ocupa de alétheia enquanto o ponto de encruzilhada dessa dupla dimensão, sabendo que não há uma sem a outra? Como falar sem calar, como dizer sem silenciar, como explicitar sem deixar implícito, como falar ou calar sem saber o momento oportuno de um ou outro gesto...? Como retirar de alguém a potência de não? Sabe-se que retirar a potência de não falar é igual a retirar a potência do próprio dizer.

É certo que Tirésias quer calar o que Édipo lhe obriga a dizer, não lhe sendo permitido silenciar pelo rei, que não lhe oferece alternativa. Em seu desejo de não dizer, de não esclarecer, de não aclarar, de não evidenciar, o cego vidente se atrasa ao encontro, afirma, apesar da ordem, da imprecação ou da proclamação, e apesar da convocação do tirano, ter sido, no fim das contas, um descuido que o levou até ali. O vidente pede para voltar, para ir embora antes mesmo que a conversa se desdobre. Ele diz que todo o interrogatório de Édipo a ele será inútil, já que sabe que de nada adiantará responder ao que lhe fora perguntado e sabe que o que disser será, para Édipo, ineficaz. Além do mais, sabe também que mesmo que cale, os fatos mostrarão o que há para aparecer. Exatamente por tentar calar o que o tirano lhe exige dizer, Tirésias é xingado, chamado de "miserável mor!" (v. 334). Quando Tirésias finalmente é levado a dizer o que sabe, ou seja, que ele, Édipo, é quem "com teu miasma contaminas Tebas" (v. 353) e que "és o matador buscado" (v. 362), a ira de Édipo passa a acusar o vidente de ser nutrido pela noite e, mais uma vez opondo luz e escuridão, de ser "incapaz/ de fazer mal a quem [como ele, Édipo] com luz convive" (v. 375), ironizando ainda o fato de ter sido ele, Édipo, e não o vidente, quem salvou os tebanos da esfinge com o pensamento (e não com os pássaros das premonições). Nesse momento, Édipo está literalmente deslumbrado com sua própria tirania.

Enquanto, com seu enigma de dizer e calar, de assumir o paradoxo da linguagem, de garantir os contrários tensivos do pensamento, dizendo, por exemplo, "o dia de hoje te expõe à luz e anula", Tirésias continua tentando defender a ambiguidade e o enigma no dizer (e, consequentemente, o esfíngico da linguagem), Édipo, querendo salvar sua busca de clareza absoluta, reclama de que o outro "fala[s] de modo obscuro e por enigmas" (v. 439). Se, a partir do episódio com a Esfinge, já escrevi sobre o Édipo enquanto uma tragédia da linguagem ${ }^{7}$, essa passagem leva Édipo Rei a ser uma tragédia da alétheia, fazendo com que seja a incompreensão tirânica do lógos e de alétheia, assim como, imbricada a ela, sua relação com o enigma da Esfinge, que, de algum modo, o levam ao pior dos desmoronamentos. Vale lembrar que, mesmo por fora da cena com Tirésias, mesmo depois dessa cena, também com outros personagens como

7 PUCHEU, Alberto. Giorgio Agamben: poesia, filosofia, crítica. Rio de Janeiro: Azougue Editorial, 2010. Capítulo 4 (sem título). 
o mensageiro e Jocasta, Édipo insiste: "Esta é a ocasião de esclarecermos tudo"; "Impossível, com base em tais indícios,/ deixar de elucidar minha origem"; "Só encerro quando tudo esclarecer"10; "Pois morrerás, calando o que não deves"11; "És um homem morto, se de novo indago"12; "Tristeza! Tudo agora transparece!"13.

Sendo a encenação de alétheia, a cena com Tirésias é a primeira em que é revelado a Édipo ser ele mesmo o assassino de Laio. Desde então, a tensão, em Édipo, entre resistência ou denegação e reconhecimento do que (h)ouve segue se dando até a cena de seu confronto com o antigo servo de Laio (o pastor a quem o então rei entregou seu filho para matar), ocorrendo, nesse momento, o desvelamento para Édipo de que ele matou o pai e se casou com a mãe tendo filhos com ela, sendo o criminoso que procura desde que Apolo mandara a cidade punilo. Não apenas isso: imediatamente depois desse momento, Jocasta se enforca, confirmando ainda mais e tornando irrefutável o que o pastor havia dito. Ele, Oidipus, ou "Eu, Oidipus", é a resposta ao enigma de Apolo, do mesmo que, sem saber, havia se implicado - implicado seu nome - ao responder o enigma da Esfinge com boi dípous (o de dois pés, os bípedes, os seres humanos). O reconhecimento de sua história ou o sentido atribuído à solução do oráculo não é, entretanto, o último passo. Há algo ainda, para além do reconhecimento, sendo mesmo necessário ultrapassar este último. O ultrapassamento do reconhecimento é o ato poético por excelência. Depois do reconhecimento, enquanto o ultrapassamento do reconhecimento, Édipo fura e, seguidamente, refura seus olhos, repetindo, de algum modo, ainda que minimamente e apenas sobre sua própria vida, a experiência que tão grandiosa e amplamente caracteriza Tirésias: se Tirésias é o cego que vê o que ninguém mais vê, que prevê o que ninguém prevê e que retrovê o não visto nem sabido do passado por ninguém, Édipo, quando finalmente vê seu passado, quando finalmente vê seu "triplo equívoco"14 (o nascer, o assassinar, o desposar), quando finalmente vê seu passado, seu presente e seu futuro, torna-se cego, cega-se. Quando a luz cede à sua investigação dos fatos pelos discursos, ela se lhe furta aos olhos. Não é fácil ver: ver cobra o preço da própria visão que enxerga. Pagando o preço da própria visão que enxerga, não é fácil tampouco ser cego; a escutar o coro, "melhor não ser do que viver na treva"

Pareceque, sóagora, comoacontecimento catastrófico, comaidaalém doreconhecimento, fazendo a experiência do não ser no ser, fazendo a experiência do que é pior do que a morte,

8 SÓFOCLES. Édipo Rei, 2007, v. 1050, p. 89.

9 Ibidem, v. 1058-1059, p. 89.

10 Ibidem, v. 1065 , p. 90

11 Ibidem, v. 1158, p. 95.

12 Ibidem, v. 1166, p. 96.

13 Ibidem, v. 1182, p. 97.

14 Ibidem, v. 1184-1185, p. 97.

15 Ibidem, v. 1368, p. 104. 
do que é pior do que a morte em vida, alétheia instaura na personagem a irreversibilidade enigmática da simultaneidade e continuidade entre (o pior do que a) morte e vida, ser e não ser, luz e sombra, claridade e opacidade, desocultamento e ocultamento, desvelamento e velamento etc. No começo da tragédia, partindo de ser o melhor, o mais poderoso, o mais sábio, o salvador e o primeiro, até fazer tal experiência catastrófica, Édipo se torna o mais triste, o mais infeliz, o com maior dor, o com maior sofrimento, o mais impuro, o mais odiado pelos deuses, o mais impotente... Em poucas palavras, o pior dos homens.

Em Édipo em Colono, o segundo movimento da trilogia tebana, temos um Édipo cego, velho, conduzido pelas mãos de uma de suas filhas, vagamundo, errante, sofredor de uma dor desumana, fantasmagórico, com o rosto decomposto, ex-corpo... Próximo à morte e ao mesmo tempo já morto em vida, procurando uma cidade que o venha a enterrar, Édipo comparece não mais em luta contra o enigma, não mais buscando ser o herói civilizador que mata o enigmático, mas, com o novo oráculo proferido que afirma que o solo que o guardar será próspero, conciliado com ele mesmo. Incluindo os contrários, Édipo fala então com a ambiguidade dos enigmas: "Me fiz alguém ao me tornar ninguém"16. Em vida, nessa vida de quem, unificando tensivamente as duas pontas, vivencia a morte e o não ser, Édipo fala a suas filhas desde o lugar do morto e do não ser. Estando à sua frente, a morte lhe está tanto atrás de si quanto em seu agora, sendo desde o lugar do morto que ele, morto-vivo, fala: "[...] Filhas,/ o pai das duas já não existe mais./ Morreu o que era meu $[. . .]^{17 ”}$. Como pode um morto falar? Como pode um morto falar em vida? Como pode um morto falar senão em vida?... Eis o traço enigmático e aporético que move a segunda tragédia da trilogia, a última escrita por Sófocles em sua velhice avançada, pouco antes de morrer. Se Édipo Rei é a dura dor da aprendizagem da aporia, Édipo em Colono é a assunção irredutível e irreversível da vida enquanto aporética: nenhum enigma a ser decifrado, mas resguardado na afirmação da aporia inultrapassável.

Voltando um pouco atrás, voltando a Édipo Rei, voltando à cena com Tirésias, logo após este revelar ser Édipo o assassino procurado pela morte de Laio, e de Édipo insensatamente acusá-lo de que trama com Creonte para este tomar o poder, o coro, no verso 485, diz, em tradução precisa e elegante de Trajano Vieira: "Aporia: dizer o quê?"18. Diante do que, a contragosto, se mostra, diante do mais inquietante ou do mais terrível, diante do que traz a desordem, diante do que desarticula, diante do que dá um sacode, diante do que confunde, diante do que perturba, diante do que não se pode aceitar nem refutar, diante do que, apesar da necessidade, não se consegue dizer, ou só se o diz pela falta de o que dizer, eis o coro,

16 SÓFOCLES. Édipo em Colono. 2005, v. 393, p. 46.

17 Ibidem, v. 1611-1613, p. 114.

18 SÓFOCLES. Édipo Rei. 2007, v. 485, p. 60. 
ele mesmo desarticulado em um impasse diante de uma vida política, a vida do personagem Édipo, tirano, tal qual re-velada por Tirésias. Nessa passagem, alétheia e aporia se sobrepõem, fazendo-nos pensar, se ainda nos for preciso usar o nome, em uma "verdade" aporética como a que poeticamente nos cabe, ou levando-nos a pensar em uma imbricação irredutível entre velamento e desvelamento, entre esquecimento e inesquecibilidade, como aporia. Pois, quando a aporia vem, ela chega nos arrebatando, tomando-nos totalmente e fazendo-nos nela, em transformação, renascermos. Na passagem 301a do Eutidemo, em tradução de Maura Iglesias, Sócrates afirma: "Eu fiquei todo enrascado em aporia, e acreditava estar sofrendo a justa pena

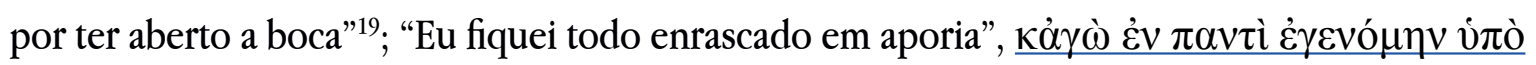
$\alpha$ topías, ser, eu caí em aporia”. A aporia nos dá um novo modo de ser, um novo vir a ser, aporético. Sendo, ao superar o recalque, o reconhecimento um dos mais importantes atos da tragédia, a

aporia é o ato, por excelência, posterior ao reconhecimento. Se há leitores do Édipo Rei que refazem em si o reconhecimento da história do herói, o leitor poético e filosófico refaz em si sua aporia inultrapassável e espantosa.

\section{Referências}

HÖLDERLIN, Friedrich. Observações sobre Édipo. IN: HÖLDERLIN, Friedrich BEAUFRET, Jean. Observações sobre "Édipo"; observações sobre "Antígona", precedido de Hölderlin e Sófocles. Trad. de Anna Luiza Andrade Coli et. al. Rio de Janeiro: Jorge Zahar Editor, 2008.

PLATÃO. Eutidemo. Trad. Maura Iglesias. Rio de Janeiro: Ed. PUC-R.J.; Edições Loyola, 2011.

PUCHEU, Alberto. Capítulo 4. In: PUCHEU, Alberto. Giorgio Agamben: poesia, filosofia, crítica. Rio de Janeiro: Azougue Editorial, 2010.

SÓFOCLES. Édipo em Colono. Trad. Trajano Vieira. São Paulo: Perspectiva, 2005.

SÓFOCLES. Édipo Rei. Trad. de Trajano Vieira. São Paulo: Perspectiva, 2007.

Submissão: $22 / 03 / 2020$

Aceite: $14 / 07 / 2020$

https://doi.org/10.5007/2176-8552.2018n26p7

Esta obra foi licenciada com uma Licença Creative Commons Atribuição-NãoComercial 4.0 Internacional.

19 PLATÃO. Eutidemo, 2011, p. 119. 